\title{
Application of a knowledge management model with the supported of social networks
}

\author{
Víctor Hugo Medina García, Lina María Medina Estrada and José Ignacio Rodríguez Molano
}

\begin{abstract}
This paper presents a knowledge management model to strengthen the relations between the university and the enterprise, and to facilitate joint strategies and interaction with social networks support.

The use of social networks in this model focuses on creating bidirectional links between the university and the enterprise, based on informal exchange of knowledge and sharing information of interest to both actors.

The expectations the model use is analyzed through the application of a survey of a population sample of colombian university students, where the results show the good attitude of these to use social networks in knowledge management to support the relations between the university and the enterprise.
\end{abstract}

Keywords - Social networks, knowledge management, entrepreneurial, university, knowledge management model.

\section{Introduction}

The boom of social networks worldwide is a phenomenon that involves the whole society, one of the social networks that has grown is Facebook, that has over one billion users worldwide, and the numbers continue to grow day by day. Due to the proliferation in the use of these networks, there is a need to involve the university academic community (professors, teachers, researchers, managers, etc.) and the business community to interact with each other through the use of available networks, to support and enhance knowledge management within the university, the enterprise and research.

When in universities knowledge management is not done correctly because of the problem with organizational learning processes. As a result, it does not have the intellectual capital expected. Hence, to develop these processes, the universities must be able to focus on a team

analysis, dissemination, use and transfer of experiences, information and knowledge among all members of an organization to generate value.

The use of social networks by the members of the academic community is a means of interaction among the academic community is known as digital culture. The role of social network in these virtual platforms between society and the possibilities they offer are many. The question is why not using them as a support tool for managing

Víctor Hugo Medina García, Lina María Medina Estrada, José Ignacio Rodríguez Molano

Distrital University "Francisco José de Caldas”, Bogotá, Colombia approach, adopting a network model. Currently universities are providing social networking facility that supports the exchange of information and communication, becoming a source of learning and continuous improvement.

For these reasons, the KM-U model (Model of Knowledge Management in University) was supplemented [1], adding a node entrepreneurial with the influence of social networks, to support a more easy and effective knowledge management within universities and interrelationships with the enterprises.

\section{Fundamentation}

Although knowledge management, today is a booming business, but in the university, members of the academic community at large number do not really know what it involves when managing knowledge. Most of them use the information that flows through processes that support activities such as learning, problem solving, strategic planning and decision making but do really understand, what is involved thereby, not adding value to the organization processes.

Man uses knowledge management to interact with others, for example the simple fact of how a father teaches his son the most basic things of life or a teacher teaches his students a particular topic, make implicitly in use [2].

Organizations today no matter what they are engaged in, they have realized that there are intangible assets that must be well managed in order to create competitive advantage and to compete in a globalized economy. Within these assets, we can find the information and knowledge what we call knowledge management. This is defined [3] as the set of processes that direct the knowledge within the university in a professional way.

To achieve this, we need a knowledge management model that links the academy, the research and the business sector with the support of ICT online with the use of social networks in order to manage information and knowledge to be generated as a result of the implementation of strategic plans in organizations.

\section{A. Social networks and knowledge management}

Internet social networks are technological support tools for interactions between people who share a common interest. They are virtualization or the abstraction computing 
Proc. of the Sixth International Conference on Advances in Computing, Electronics and Communication - ACEC 2017. Copyright $(C$ Institute of Research Engineers and Doctors. All rights reserved.

ISBN: 978-1-63248-138-2 doi: 10.15224/ 978-1-63248-138-2-11

social networks previously built and maintained through face interaction. These social networking websites, represented through tools such as Facebook, MySpace, Twitter, LinkeId, Blogger and others are just very evolved expression with a significant technological component (Web 2.0) of previously existing social networks, which have revolutionized our old forms of interaction with sociocultural change in people and society.

Knowledge has been channeled in a particular manner either in restricted, centralized, maximizing initiatives aimed to codify explicit knowledge, the ideal of conventional enterprise because it is easier to transfer, knowledge is often viewed as a resource or object and not an act. However, today it is more important to have the flow and exchange, of knowledge because of the rapid obsolescence of knowledge in all fields. This phenomenon requires us to have an organizational change that allows the activation of more channels of exchange and creation of knowledge for University-Enterprise relationship, as well as finding a way of renewal and sustainability [2].

Knowledge management has critical factors that determine their success; these are related to having an organizational culture that values cooperation, collaboration, diversity and complementarity, good levels of trust and communication among employees or members of the academic community.

Connecting people individually or in groups using a variety of forms can be an important source of new ideas and help organizations to extend and develop their skills. Social networks can be used to store all the relevant information and highlight the necessary information for a specific need or unusual information. Some organizations provide "yellow pages" of who knows what, while other key personnel identified what is connected to the social network and part of the work is to provide the appropriate links.

\section{B. Analysis of the study case}

Given that research previously undertaken have dealt with the analysis of business cases where it have implemented knowledge management programs in the last years, this research focused on analyzing the Knowledge Management Model in University - KM-U (see Figure 1 [1], [4] and then based on that, develop a model that integrates the enterprise with social networks.

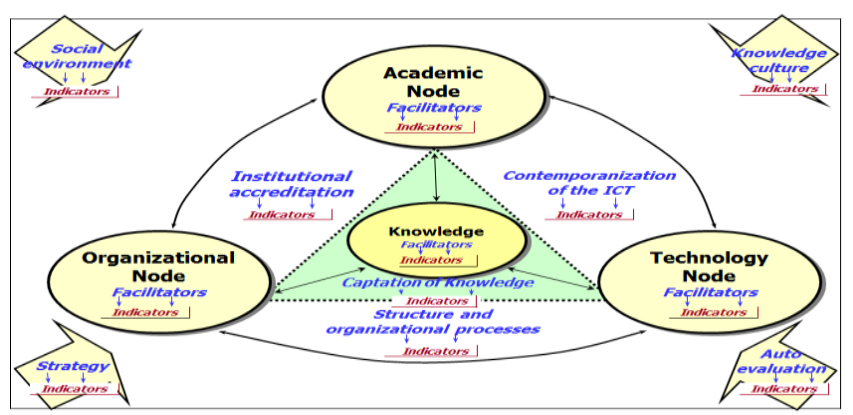

Figure 1 Organizational Model of Knowledge Management in University. Source: Medina [1].

\section{Knowledge management model proposed}

The proposed model is based on an extension of the KM-U model analyzed previously by using social network.

The model expresses the need to connect the external environment through the internal management process based on knowledge. The model is based on four interconnected nodes, which are supported by different types of social networks. The nodes identified are: Academic, Organizational, technological and entrepreneurial, with the latter node the proposal to strengthen relations between the university and Enterprise (see Figure 2).

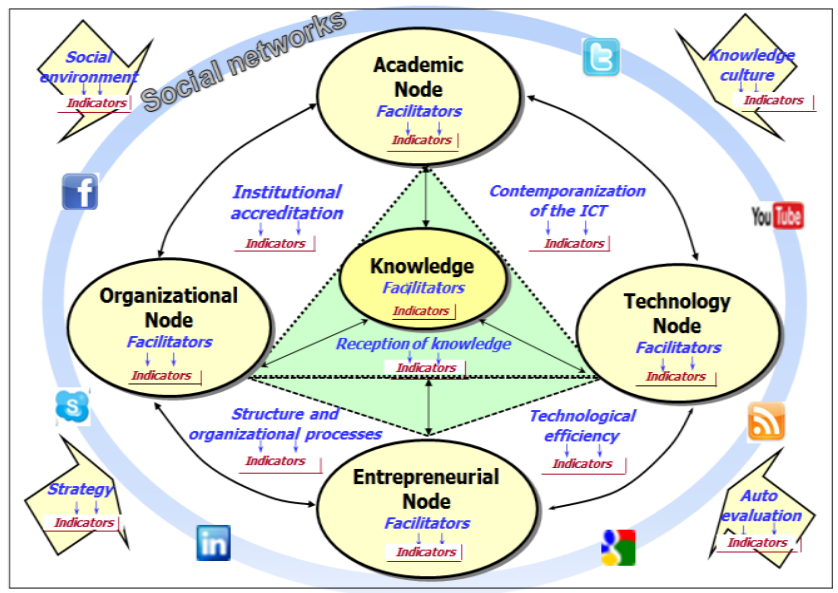

Figure 2 Knowledge management model support by social networks as facilitator the relations University-Enterprise. Source: Adaptation and extensión GC-U Model.

The core of the model is the knowledge, which will be enriched by the experience-based knowledge that can bring in the entrepreneurial node. The nodes are fed by both internal and external facilitators. External facilitators comprising: (Social environment, cultural knowledge, strategies and self-assessment) focus on developing strategic action policies of the university in its socio environment. Internal facilitators also kept, by creating an additional one, called overcoming technological deficiencies. These facilitators are aimed at developing operational tactics and actions to achieve the principles and purposes of the educational projection specific to each university.

\section{A. Nodes and subnodes}

The nodes are knowledge-based resources, which generates, transfers knowledge and can perform various processing functions that required treatment internally or through network links. The nodes of the model are: 
- Knowledge Node or Core: This is the main axis model since this node serves as a repository of knowledge. It shows how to generate and disseminate knowledge at the university and the enterprise.

- Academic Node: Refers to the activities of the academic area such as: the production of knowledge, professional training, and social culture. The teaching and research are part of these activities usually seek training in the service of human society and the expansion of human knowledge.

- Organizational Node: this node functions involve guidance and support to enable university activities and relate specifically to the leadership, direction, supervision and control of the financial and administrative affairs of the university and all its dependencies.

Knowledge and organization are two central aspects of the necessary transformation of the university, although theoretically these two aspects should be inextricably linked, the current situation shows that it is not. Therefore it is necessary to create new relationships between the different actors of the university as well as a different concept for the administration of resources, where knowledge is part of this vital, new ways to learn and to link with the surroundings.

Technology Node: Is the infrastructure available that creates, access, and disseminate knowledge. This includes standard programs developed to measure access to telecommunications, intranet, extranet and user support and all locally or remotely. Using these tools and participating employees share the content on their daily work processes. They also facilitate the learning process by allowing the organization and storage of knowledge.

To have access to Internet and to be possible to use the existent social networks to transfer the knowledge becomes indispensable in the use of the model, since this whole process is based in the use of this networks, with this it can make sure that the characteristics of the knowledge will be easy to identify, its distribution in a massive way goes to be much easier, and allowing the analysis and the necessary interaction for its development will be guaranteed.

- Entrepreneurial Node: Universities and enterprises are primary actors in innovation processes and both possess skills and fundamental scientific and technological capabilities to generate knowledge that are often complementary. The knowledge generated in one area can be different and, therefore, complementary, in respect of what takes place in other business institutions. In order to develop science and technology, both universities and businesses require financial resources, infrastructure and human capital which often do not have partners or whose costs can't be afforded. In general, the research and development projects are very long term activities with uncertain results and involve large sums of money. Moreover, despite the need to share to develop and use capabilities to generate scientific and technological knowledge, the university and the company carried out this task with responsibility, goals and criteria very different and sometimes difficult to reconcile.

Generally, universities are dedicated to training and knowledge generation in science and technology through basic research, therefore establishing a virtuous synergy between these functions and financed with equity. The purpose and use of the results of such research are typically academics, which encourages its dissemination in the scientific community for evaluation and development of further research.

Enterprises, on the contrary, need to pursue innovation processes to increase productivity and competitiveness, especially in dynamic sectors, which are motivated by other interests. Most of the time, the market is the main incentive mechanism to the introduction of innovations originating in the results of applied research, and the appropriateness and cost-effectiveness of such innovations are the main criteria for evaluation.

The subnodes or detailed knowledge resources initial model described in Figure 2, but the subnodes that could be implemented in the proposed Entrepreneurial Node can be summarized in:

- Services.

- Innovation.

- University-Enterprise projects.

- Research projects.

- Other that consider the organization.

The detail of all the subnodes is schematized in the following Figure 3:

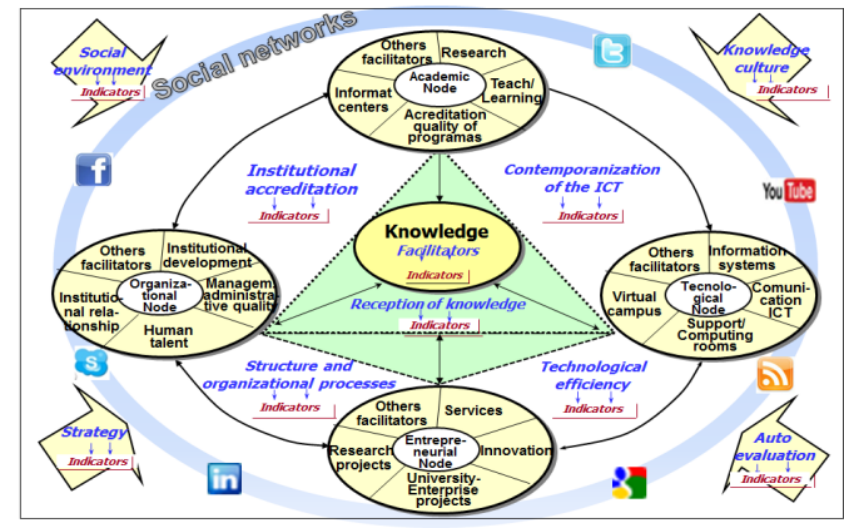

Figure 3 Knowledge management model support by social networks as facilitator the relations University-Enterprise. Source: Adaptation and extensión GC-U Model.

For those nodes and subnodes facilitators agents and indicators are explained below. 


\section{B. Agents facilitators and indicators}

Organizations need to obtain results that are coming through the behavior of their agents facilitators, that is to say, their personnel's performances and the operation of their processes [5].

In higher education institutions the agents facilitators are the elements that will promote activities that allowed the university organizational policy and management or compliance with actions that evaluated according to the behavior of a number of indicators that facilitate the identification, development and retention of knowledge and ultimately help sustain and fulfill the mission of the organization.

Because the entrepreneurial node was added to the model, some facilitators that arise for this node are:

- Flow of human resources.

- Informal contacts between professionals.

- Popularization activities and diffusion of the knowledge.

- Joint Projects.

- Technology-based companies.

Because the entrepreneurial node was added the model, the following table it explains each one of its facilitators, its indicators and the form of corresponding construction.

\section{Interaction model with social networks}

Informal networks of work, such as creating informal contacts between professionals, teachers, researchers, students and other members of the academic community involve bidirectional links between universities and industry, based on informal exchange of knowledge, information sharing. In these networks, the flow of knowledge is tacit and poorly coded and incorporated in people, enabling knowledge sharing in a relationship, however, is less formalized in research projects and longterm development.

Companies often use and positively assess these informal networks of professionals. Besides facilitating contact with qualified human resources, these channels are used to obtain information on trends in research and development and access to scientific and technological knowledge to develop professionals in universities. On the side of universities, these networks represent a way of circulating the progress of investigations and submit them for evaluation by professionals who are users of the applications of this knowledge. In this sense, informal networks and professionals can be a way to begin to articulate the range of scientific and technological knowledge built on experience of professionals with business requirements, constituting good channels to identify collaborative projects or future scientific oint research [6].

\section{Attitudes and expectations of the use of knowledge management model supported by social networks}

Social networks can be used in education to help learning. It is particularly useful for collaborative work, understood as the exchange and development of knowledge on the part of small groups, aimed at achieving academic purposes, it can used as a platform for consolidation of certain communities, which in our case would be a community made up of the academy and university. Using social networks in collaborative work promotes motivation, higher levels of academic performance, enables individual learning and group feedback, improves retention of learning, critical thinking power, multiply the diversity of knowledge and experience acquired [7].

\section{A. Research context}

This research was carried out to study the attitudes of students from different semesters at the School of Engineering at the University Sergio Árboleda, on social networks and their use in the context of knowledge management model supported by social networks. In this study, we sought to examine the degree of knowledge and use of social networks of our students, using a questionnaire sent by e-mail account to each student, designed specifically for this research. We want to and which in indicate the attitude of our students in the didactic use of these platforms for interaction.

\section{B. Data analysis}

Of all students enrolled in the School of Engineering, a sample of 72 students was involved in the survey. Data analysis results were obtained from in the some questions as an example:

- Is there any social network activity currently in use?

What social networks do you know at the moment?

- Do you use the social network from your own initiative or from the professors? To the question it has used the social networks academically, for a professor's suggestion or for own initiative?

- How long do you connected to the social networks daily?

- What you would like to use for practical academic and managerial?

- What is the possibility that social networks can be used day by day in the academic processes? (Table I).

\begin{tabular}{|l|c|c|}
\hline \multicolumn{1}{|c|}{ Activities } & Answers & Percentage \\
\hline To share document & 58 & $81 \%$ \\
\hline To share pictures & 35 & $49 \%$ \\
\hline $\begin{array}{l}\text { To foment the communication among } \\
\text { enterprise-university }\end{array}$ & 53 & $74 \%$ \\
\hline To share knowledge among educational & 28 & $39 \%$ \\
\hline To share knowledge among students & 36 & $50 \%$ \\
\hline $\begin{array}{l}\text { To share knowledge among educational } \\
\text { and students }\end{array}$ & & $\begin{array}{l}\mid \\
\text { To share knowledge among users }\end{array}$ \\
\hline To foment the communication & & \\
\hline $\begin{array}{l}\text { To share the knowledge that is generated } \\
\text { between university and company }\end{array}$ & 28 & $39 \%$ \\
\hline
\end{tabular}


Proc. of the Sixth International Conference on Advances in Computing, Electronics and Communication - ACEC 2017. Copyright (C) Institute of Research Engineers and Doctors. All rights reserved. ISBN: 978-1-63248-138-2 doi: 10.15224/ 978-1-63248-138-2-11

Table I. ACTIVITIES OF KNOWLEDGE MANAGEMENT THAT CAN BE REALIZED THROUGH THE SOCIAL NETWORKS

- Are you willing to use the social nets to negotiate the knowledge generated by the daily activities of the university?

\section{Analysis of results}

Analysis of the data from the answers received from the survey provides us the following results. On one hand, students have a good attitude about the use of social networks and many were users. Knowledge and use social networks by some of students were especially high. This shows that there is an absence of mistrust for $\mathrm{t}$ using them. In analyzing the use of social networks academically, it is clear that a very high percentage has been used for this purpose, either on students own initiative or on the recommendation of teachers. As for the time spent online the highest percentage was in the range between one and three hours days it indicates that the time spent likely to suggested that knowledge management was indeed happened through this medium. The use of social networks was preference for more than $50 \%$. Of the people surveyed. To share knowledge regardless of where it is generated, it is necessary to use a social network to make this process efficient and effective.

The published form is available at the following link: https://docs.google.com/spreadsheet/viewform?formkey=dg 9szzbzcvrxmxhfznk5vwpia01 mnke6mq

\section{v. Conclusions}

It is important to understand that knowledge management will establish a knowledge center (brain) based on technology (hardware and software), rather it serves as the necessary routes (nervous system based on conversational networks) to the natural flow of knowledge within institutions. As we know the main goal of knowledge management resides in the creation of value (survival of the system).

The model has been developed thinking of the general requirement for organizations to create value and the disposition of the resource 'knowledge' as the key factor for generating of sustainable competitive advantages. From the hypothesis outlined in this research we can reaffirm that, in implementing the model at any university and specifically in Colombia, one can overcome the gap between academia and business, using social networks to share information, knowledge and experiences obtained, in order to provide the country with better social and economic benefits. This is because any country that wants to incentives the cooperation of universities with industry must move simultaneously in the definition of productive structures that require a higher level of knowledge.

\section{Acknowledgments}

Work done in collaboration with the Distrital University "Francisco José de Caldas" of Bogotá D.C., Colombia, (http://www.udistrital.edu.co).

\section{References}

[1] Medina, Víctor H.: Modelo Organizacional y Tecnológico para la Gestión del Conocimiento en la Universidad: Aplicación en la Universidad Distrital". Tesis Doctoral. Universidad Pontificia de Salamanca Madrid (2004)

[2] Arboníes, Ángel: "Conocimiento para innovar: cómo evitar la miopía en la gestión de conocimiento" Madrid (2006)

[3] Davenport, T.H. and Prusak L. Working knowledge: How organizations manage what they know. Boston, MA: Harvard Business School Press (1998)

[4] Medina V. H. Pérez M. F. "Knowledge Management Model for Fruit_Horticultural Agroindustry. Case: Córdoba - Colombia", in International Journal of Future and Comunication, Vol. 2 Number 6, ISSN 2010-3751, págs. 617- 622, Edit for IACSIT Press http://www.iacsitp.com. December 2013. Singapore. http://www.ijf cc.org (2013)

[5] Benavides, C., Quintana García: Gestión del conocimiento y calidad total. Ed Díaz de Santos, Madrid (2003)

[6] Santana, M, Cabello, J. Cubas, R. Medina V.: Redes sociales como soporte a la gestión del conocimiento". Universidad ESAN, Lima (2011)

[7] Horibe, F.: Managing Knowledge Workers. John Wiley \& Sonns, Canadá (1999)

About authors(s)

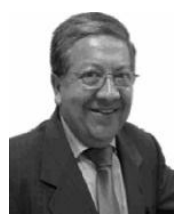

Víctor Hugo Medina García. He is $\mathrm{PhD}$ degree in Computer Engineering from the Pontificia of Salamanca University, He is currently a researcher and senior lecturer at the Faculty of Engineering at the Distrital University "Francisco José de Caldas" in Bogotá - Colombia, where he is Extension Director of Engineering Faculty.

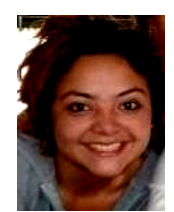

Lina Maria Medina Estrada. She is Master in Education, Intercultural Communication, Ethnic education and cultural diversity of the Distrital University "Francisco José de Caldas" of Colombia and graduated in Social Communication and Journalism and the Pontificia University Javeriana. He is $c$ urrently Independent consultant

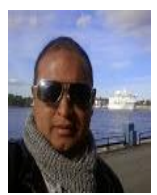

José Ignacio Rodriguez Molano. $\mathrm{He}$ is $\mathrm{PhD}$ degree in Computer Engineering from the Oviedo University, $\mathrm{He}$ is currently a researcher and senior lecturer at the Faculty of Engineering at the Distrital University "Francisco José de Caldas" in Bogotá - Colombia, His area of work and research is entrepreneurship and social networks. 